\title{
Impact of transcatheter aortic valve implantation on the left ventricular mass
}

\author{
Hacı Ahmet Kasapkara ${ }^{1}$, Hüseyin Ayhan ${ }^{1}$, Cenk Sarı ${ }^{2}$, Abdullah Nabi Aslan ${ }^{2}$, \\ Hakan Süygün ${ }^{1}$, Serdal Baştuğ ${ }^{2}$, Tahir Durmaz ${ }^{1}$, Telat Keleş ${ }^{1}$, Engin Bozkurt ${ }^{1}$ \\ ${ }^{1}$ Department of Cardiology, Faculty of Medicine, Yıldırım Beyazıt University, Ankara, Turkey \\ ${ }^{2}$ Department of Cardiology, Ankara Ataturk Education and Research Hospital, Ankara, Turkey
}

\begin{abstract}
Background: Aortic stenosis (AS) induces pressure overload of the left ventricle (LV) and results in left ventricular hypertrophy. The remodeling of the LV in patients with AS is a complex process including structural and functional disturbances. After aortic valve replacement, reverse remodeling of $L V$ begins. The aim of this study was to evaluate the impact of transcatheter aortic valve implantation (TAVI) on LV mass (LVM) in early and mid-term follow-ups after the procedure.
\end{abstract}

Methods and Results: We enrolled consecutive 75 patients who underwent successful TAVI. Transthoracic echocardiography was performed prior to TAVI and at hospital discharge, in the $1^{\text {st }}$ month and $6^{\text {th }}$ month of the follow-ups. The mean LV ejection fraction improved significantly after TAVI (54.2 $\pm 15.0 \%$ to $57.3 \pm 11.7 \%, p<0.001)$. There were no significant changes between the baseline and discharge mean LVM and LVM index values (LVMI; $p=0.1$ ). However, LVMI decreased significantly in the $1^{\text {st }}$ month of follow-up compared to baseline (123.3 \pm \pm 20.3 to $127.9 \pm 21.3 \mathrm{~g} / \mathrm{m}^{2}$, respectively, $\left.p<0.001\right)$. Also, significant regression of LVM was observed at the $1^{\text {st }}$ month of follow-up compared to baseline $(228.3 \pm 33.5 \mathrm{~g}$ vs. $236.5 \pm 34.2 \mathrm{~g}$, respectively, $p<0.001)$. Furthermore, the significant regression in both of LVM and LVMI continued at $1^{\text {st }}$ and $6^{\text {th }}$ months of the follow-ups $(p<0.001)$.

Conclusions: A significant regression of LVM was observed after TAVI. These changes may have prognostic value in patients with severe AS. (Cardiol J 2015; 22, 6: 645-650)

Key words: aortic valve stenosis, TAVI, left ventricular mass

\section{Introduction}

Degenerative aortic valve stenosis (AS) is the most common valvular heart disease in the elderly population and it has an increasing prevalence with age [1-3]. AS induces pressure overload of the left ventricle (LV) and results in left ventricular hypertrophy (LVH). Myocyte degeneration and fibrosis have major roles in the pathophysiology of hypertrophic remodeling. LVH caused by AS is associated with systolic and diastolic dysfunction of the LV which are the recognized risk factors of cardiac morbidity and mortality [3]. Transcatheter aortic valve implantation (TAVI) has been proven to be a promising therapy for high risk or inoperable patients with AS [4].

Left ventricular remodeling in patients with AS is a complex process including structural and functional disturbances. After aortic valve replacement (AVR), reverse remodeling of the LV begins. This way, LV volume and mass regress, LV systolic and diastolic function improves. This

Address for correspondence: Hüseyin Ayhan, MD, Ankara Ataturk Education and Research Hospital, Department of Cardiology, Street: Bilkent Postal code: 06800, Ankara, Turkey, tel: +90 3122912525, fax: +90 3122912745, e-mail: huseyinayhan44@yahoo.com 
process seemed to be important for prognosis and symptomatic improvement after open surgery $[5,6]$. The early- and late-term effects of TAVI on LV mass (LVM) and volume regression and LV diastolic dysfunction have controversial data in the literature. The aim of this study was to evaluate the impact of TAVI on LVM in early and mid-term follow-ups.

\section{Methods}

\section{Patients}

We consecutively recruited 75 patients who underwent TAVI using balloon-expandable Edwards Sapien XT (Edwards Lifesciences, Irvine, CA, USA) prostheses between July 2011 and July 2013. The study population included symptomatic patients with severe AS (mean gradient $\geq 40 \mathrm{~mm} \mathrm{Hg}$ and/or aortic valve area [AVA] $<1 \mathrm{~cm}^{2}$ or indexed AVA $\leq 0.6 \mathrm{~cm}^{2} / \mathrm{m}^{2}$ ) and inoperable or at high risk for surgical AVR (s-AVR) due to co-morbid conditions. The exclusion criteria were as follows: any contraindications to anticoagulant and/or antiplatelet agents, life expectancy with or without AVR < 12 months, non-calcified valve, history of AVR, severe aortic or mitral regurgitation, severe renal insufficiency, coagulopathy or bleeding diathesis and abdominal aortic aneurysm. Before the procedure, all patients underwent transthoracic echocardiography (TTE), transesophageal echocardiography (TEE), multislice computed tomography (MSCT) and coronary angiography. Pretreatment operative risk was assessed by the Logistic European System for Cardiac Operative Risk Evaluation (EuroSCORE) and the Society of Thoracic Surgeons (STS) score.

All patients were informed before the procedure, and the study was approved by our hospital's ethics committee.

\section{Transthoracic echocardiography}

All patients underwent TTE (IE33 echocardiography system, Philips Medical Systems, Eindhoven, the Netherlands) with an experienced operator. TTE Doppler and 2-dimensional images were obtained from parasternal short and long axis, apical 4-chamber, and subcostal 4-chamber views. TTE was reviewed to assess the valve morphology, valvular anatomy, aortic annulus diameter, ventricular function, and pericardium. It was performed prior to TAVI and at hospital discharge, in the $1^{\text {st }}$ month and $6^{\text {th }}$ months of the follow-ups.

The Doppler echocardiographic measurements included LV end-diastolic volume, LV ejection fraction (LVEF) calculated with the modified Simpson's method, transvalvular pressure gradient determined by the Bernoulli formula, and AVA calculated by the continuity equation. Patients with low flow and low gradient AS underwent dobutamine stress echocardiography in order to determine the exact severity of AS and LV contractile reserve. LVM was calculated with the formula as follows: $\mathrm{LVM}=$ $0.8 \times\left(1.04 \times\left[\left(\right.\right.\right.$ LVEDD + LVPWTd + LVSWTd $^{3}$ $\left.\left.+(\text { LVEDD })^{3}\right]\right)+0.6 \mathrm{~g}$ [7], where LVEDD is left ventricular end diastolic diameter; LVPWTd — left ventricular posterior wall thickness diameter, and LVSWTd - left ventricular septal wall thickness diameter. LVM index (LVMI) was determined by using the formula, LVM/body surface area $\left[\mathrm{g} / \mathrm{m}^{2}\right]$. LVH was defined as LVMI $>95 \mathrm{~g} / \mathrm{m}^{2}$ for women and LVMI $>115 \mathrm{~g} / \mathrm{m}^{2}$ for men. All echocardiographic parameters were evaluated according to guidelines of the American Society of Echocardiography [8].

\section{Transcatheter aortic valve implantation}

TAVI was performed at the catheterization laboratory with fluoroscopy using conventional technique. Seventy-two (96\%) through femoral artery and $3(4 \%)$ patients through subclavian artery received a balloon expandable Edwards Sapien XT (Edwards Lifesciences, Irvine, CA, USA) aortic valve. The sizes of the valves used were $23 \mathrm{~mm}$, $26 \mathrm{~mm}$ and $29 \mathrm{~mm}$. It was decided with combined multimodal imaging methods like TTE, TEE and MCST.

\section{Statistical analysis}

All analyses were performed using SPSS version 19.0 (IBM Corporation, Armonk, NY). Continuous variables are presented as mean, standard deviation (SD) and were compared by means of a 2 -sided students T-test. Categorical data were expressed as frequency (percentages) and compared using the $\chi^{2}$ and Fisher's exact tests. Echocardiographic data obtained at baseline; discharge, $1^{\text {st }}$ month and $6^{\text {th }}$ month were compared by repeated measures ANOVA. Continuous variables were compared between patients before and after TAVI using the paired Student's t-test (for normally distributed variables) or the Wilcoxon test (for not-normally distributed variables). Significance was accepted as $\mathrm{p}<0.05$.

\section{Results}

\section{Patients}

Demographic and clinical characteristics of the study population were presented in Table 1 . The mean age of the patients was $77.8 \pm 7.8$ years. Thirty-eight point seven percent of the patients 
Table 1. Basal characteristics and procedural features.

\begin{tabular}{|c|c|}
\hline Patient characteristics & All patients $(n=75)$ \\
\hline Male/female & $38.7 \% / 61.3 \%$ \\
\hline Age [year] & $77.8 \pm 7.8$ \\
\hline Body mass index $\left[\mathrm{kg} / \mathrm{m}^{2}\right]$ & $27.6 \pm 5.2$ \\
\hline NYHA II & $8 \%$ \\
\hline NYHA III & $64 \%$ \\
\hline NYHA IV & $28 \%$ \\
\hline STS & $7.4 \pm 5.6$ \\
\hline \multicolumn{2}{|l|}{ SURTAVI: } \\
\hline Low risk & $9.3 \%$ \\
\hline Moderate risk & $33.3 \%$ \\
\hline High risk & $57.3 \%$ \\
\hline EuroScore [\%] & $21.8 \pm 16.5$ \\
\hline \multicolumn{2}{|c|}{ Associated comorbid conditions } \\
\hline Coronary artery disease & $72.0 \%$ \\
\hline Hypertension & $81.3 \%$ \\
\hline Diabetes mellitus & $26.7 \%$ \\
\hline Hyperlipidemia & $45.3 \%$ \\
\hline Smoker & $20.0 \%$ \\
\hline \multicolumn{2}{|l|}{ COPD: } \\
\hline Mild & $44.0 \%$ \\
\hline Moderate & $30.7 \%$ \\
\hline Severe & $22.7 \%$ \\
\hline Peripheral arterial disease & $30.7 \%$ \\
\hline Atrial fibrillation & $28.0 \%$ \\
\hline \multicolumn{2}{|l|}{ Echocardiographic variables } \\
\hline LVEDD [cm] & $4.67 \pm 0.7$ \\
\hline LVESD $[\mathrm{cm}]$ & $3.05 \pm 0.9$ \\
\hline IVS (cm) & $1.33 \pm 0.2$ \\
\hline Posterior wall thickness [cm] & $1.27 \pm 0.1$ \\
\hline Maximal gradient [mm Hg] & $87.5 \pm 23.2$ \\
\hline Mean gradient [mm Hg] & $53.3 \pm 14.8$ \\
\hline Aortic valve area $\left[\mathrm{cm}^{2}\right]$ & $0.6 \pm 0.1$ \\
\hline LVEF [\%] & $54.2 \pm 15.1$ \\
\hline Peak SPAP [mm Hg] & $47.2 \pm 14.4$ \\
\hline \multicolumn{2}{|l|}{ Aortic regurgitation: } \\
\hline Mild & $54.6 \%$ \\
\hline Moderate & $5.3 \%$ \\
\hline Severe & $1.3 \%$ \\
\hline \multicolumn{2}{|l|}{ Mitral regurgitation: } \\
\hline Mild & $56.0 \%$ \\
\hline Moderate & $6.7 \%$ \\
\hline Severe & $1.3 \%$ \\
\hline Femoral vascular closure & $85.5 \%$ \\
\hline Local anesthesia & $80 \%$ \\
\hline \multicolumn{2}{|l|}{ Valve diameter [mm]: } \\
\hline 23 & $40 \%$ \\
\hline 26 & $33 \%$ \\
\hline 29 & $2 \%$ \\
\hline Contrast used [cc] & $201.5 \pm 55.7$ \\
\hline $\begin{array}{l}\text { Duration of discharge } \\
\text { after procedure [day] }\end{array}$ & $7.3 \pm 5.3$ \\
\hline
\end{tabular}

NYHA - New York Heart Association; STS - Society of Thoracic Surgeons, COPD - chronic obstructive pulmonary disease; LVEDD - left ventricular end diastolic diameter; LVESD - left ventricular end systolic diameter; IVS - interventricular septum thickness; LVEF - left ventricular ejection fraction; SPAP - systolic pulmonary artery pressure

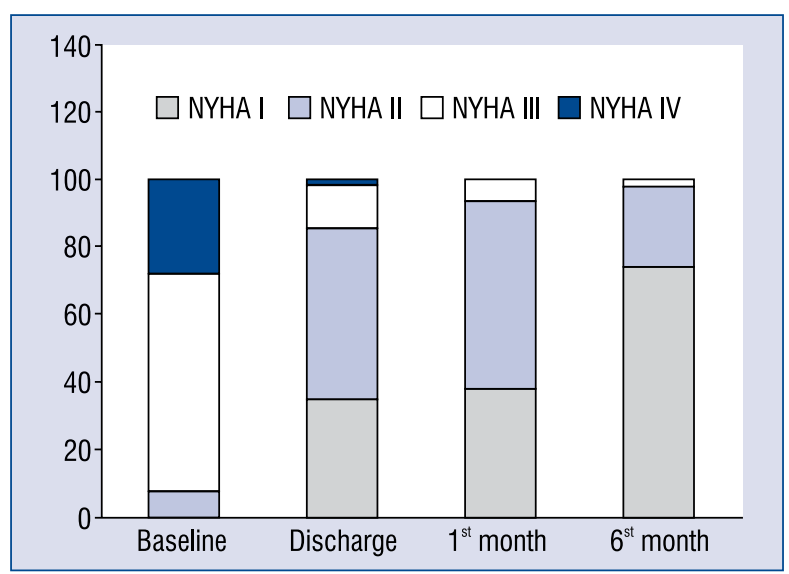

Figure 1. Changing functional capacity after transcatheter aortic valve implantation; NYHA - New York Heart Association.

were male, whereas $61.3 \%$ were female. According to New York Heart Association classification, 93\% of the patients were in functional class III and IV (Fig. 1). Past history revealed coronary artery disease in $70 \%$, hypertension in $82 \%$, diabetes mellitus in $27 \%$, and peripheral artery disease in $34 \%$ of the patients. The STS score of the patients was $7.3 \pm$ $\pm 5.2 \%$ and mean logistic EuroSCORE was $21.8 \pm$ $\pm 16.5 \%$. According to the SURTAVI risk model, $90.6 \%$ of patients were in the moderate and high risk groups.

\section{Transcatheter aortic valve implantation}

TAVI was performed with conventional technique under general (42 patients) and local anesthesia (33 patients). Acute procedural success rate was $100 \%$. In all subjects, balloon-expandable Edwards Sapien XT (Edwards Lifesciences, Irvine, CA, USA) valve was deployed through femoral (72 patients) and subclavian artery (3 patients) route. Three valve sizes of $23 \mathrm{~mm}, 26 \mathrm{~mm}$ and $29 \mathrm{~mm}$ were available. Patients were heparinized during the procedure to achieve an activated clotting time of 250-300 s and all procedures were performed successfully. For access site closure, vascular closure devices were used in 72 patients while surgical closure was used in the remaining patients. Stable patients were discharged from the hospital and follow-ups at $1^{\text {st }}$ and $6^{\text {th }}$ months were planned. During the follow-ups, routine physical examinations, TTE and functional capacities were evaluated.

TAVI was performed by a $100 \%$ procedural success rate. However, a second valve has been required in 2 patients, first due to the lower locali- 


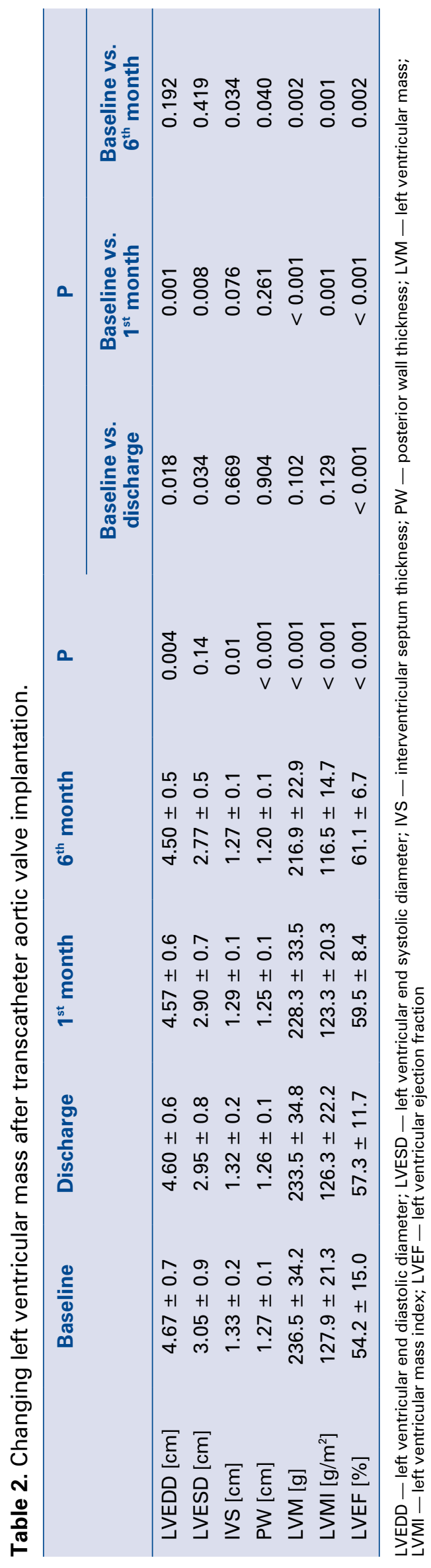

zation and second due to valve embolization. After the procedure, totally 5 in-hospital mortalities were recognized because of the right ventricular rupture due to rapid pacing (in 2 patients), LV rupture due to wire in the LV, postoperative bleeding via supra-aortic approach and left main coronary artery obstruction due to the shift of aortic cusp calcification.

\section{Transthoracic echocardiography results before and after the procedure}

Transthoracic echocardiographic parameters at baseline and during follow-ups were shown in Table 2. Clinical follow-ups of all patients were done in our hospital. All patients had severe AS with a mean AVA of $0.62 \pm 0.17 \mathrm{~cm}^{2}$ and average mean aortic valve gradient of $53.3 \pm 14.8 \mathrm{~mm} \mathrm{Hg}$. Mean baseline LVEF was $54.2 \pm 15.1 \%$.

Significant hemodynamic improvement has been observed after TAVI. Mean transvalvular aortic valve gradient decreased significantly from $53.3 \pm 14.8 \mathrm{~mm} \mathrm{Hg}$ to $9.22 \pm 3.33 \mathrm{~mm} \mathrm{Hg}$, $(\mathrm{p}<0.001)$. Also, a statistically significant increase was observed in LVEF compared to baseline at discharge, and in the $1^{\text {st }}$ and $6^{\text {th }}$ months of followups $(54.2 \pm 15.0 \%$ vs. $57.3 \pm 11.7 \%$ vs. $59.5 \pm$ $\pm 8.4 \%$ vs. $61.1 \pm 6.7 \%$, respectively, $\mathrm{p}<0.001$ ). Both LVM and LVMI values decreased at discharge compared with baseline, but these did not reach statistical significance with value of $\mathrm{p}=0.10$ and $\mathrm{p}=0.12$, respectively. At $1^{\text {st }}$ month, $\operatorname{LVM}(228.3 \pm$ \pm 22.9 g vs. $236.5 \pm 34.2 \mathrm{~g}$, respectively, $\mathrm{p}<0.001)$ and LVMI $\left(123.3 \pm 20.3 \mathrm{~g} / \mathrm{m}^{2}\right.$ vs $127.9 \pm 21.3 \mathrm{~g} / \mathrm{m}^{2}$, respectively, $\mathrm{p}<0.001$ ) reduced significantly compared with baseline and also these regressions continued and reached the statistical significance at the $6^{\text {th }}$ month of follow-up ( $\left.<<0.001\right)$ (Table 2, Fig. 2). During the $6^{\text {th }}$ month of the follow-up, it was detected that diastolic diameter of $\mathrm{LV}$ posterior wall thickness regressed significantly from $1.27 \pm 0.1 \mathrm{~mm}$ to $1.20 \pm 0.1 \mathrm{~mm}(\mathrm{p}<0.001)$ in addition to interventricular septum diastolic wall thickness which regressed from $1.33 \pm 0.1 \mathrm{~mm}$ to $1.27 \pm 0.1 \mathrm{~mm}$ $(\mathrm{p}=0.01)$.

Echocardiographic follow-ups were achieved in $95 \%$ and $85 \%$ of patients at $1^{\text {st }}$ month and $6^{\text {th }}$ month, respectively. A statistically significant improvement has been monitored in valve functions (mean gradient, AVA) at discharge and follow-ups after TAVI. There was no severe paravalvular aortic regurgitation in any patients after TAVI and at follow-ups. Only 4 (3.8\%) patients required permanent pacemaker because of complete atrioventricular block. The length of mean hospital stay was $7.3 \pm 5.3$ days. 


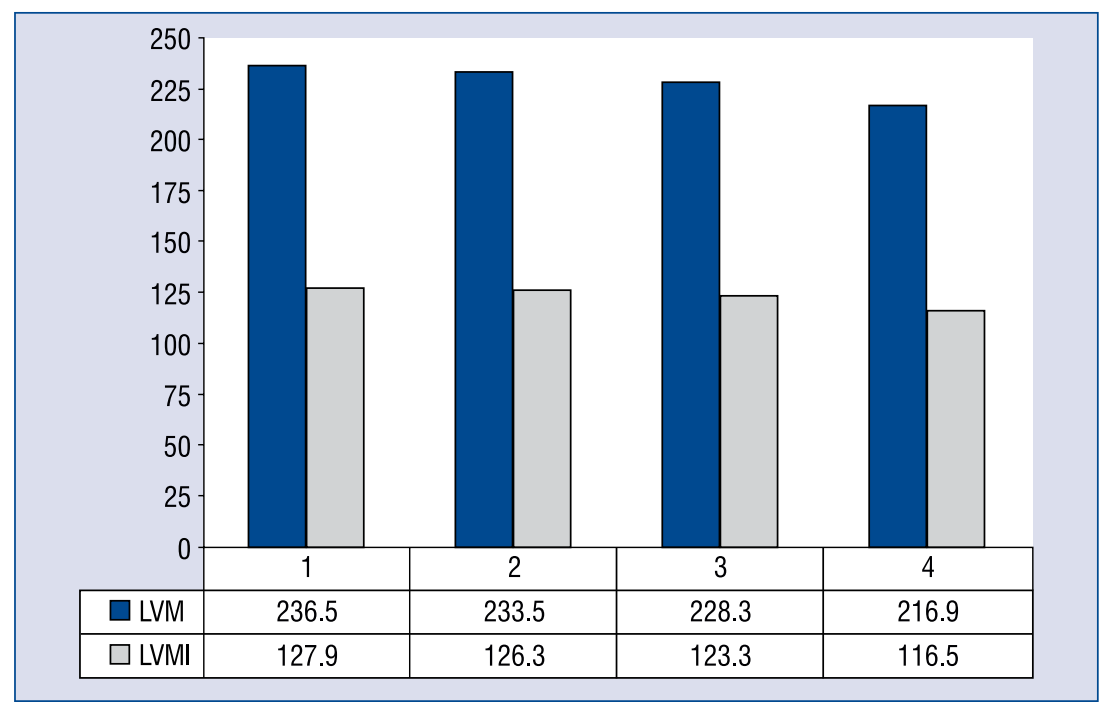

Figure 2. Changing left ventricular mass (LVM) and left ventricular mass index (LVMI) with transcatheter aortic valve implantation.

\section{Discussion}

Degenerative AS is one of the most common acquired valvular heart diseases. The mortality rate, especially in older patients, related to severe AS is high. The excessive pressure overload induced by AS results in LVH which in turn leads to an increased risk of heart failure, cerebrovascular accident and sudden cardiac death [9]. Therefore, the prognosis of patients with symptomatic AS accompanying severe LVH is worse.

Increase in LVM is an independent risk factor for adverse cardiovascular events and mortality $[10,11]$. LVMI is an index used in the evaluation of LVH. It is known that, LVMI decreases with the reduction of LV afterload after s-AVR and as a result, improvement in myocardial ischemia, functional capacity and long-term prognosis is observed $[12,13]$. The regression in LVMI after sAVR is believed to be more important than valvular gradient as a prognostic factor [14-16]. The rate and magnitude of regression in LVMI can also be used as a distinctive parameter for reverse cardiac remodeling [17]. The decline of LVMI after s-AVR can differ depending on variables such as patient's age, prosthesis size, valvular gradient, patientprosthesis mismatch and surgical method. The long-term outcomes have been demonstrated to be better in patients showing rapid regression in $\mathrm{LVH}$ after surgery compared to others. In a vast majority of study, it was demonstrated that the regression of LVM after s-AVR is chiefly observed in the $1^{\text {st }}$ year and, generally, the final measurement of regression in LVM is accepted to be reached approximately in the first 6 months of follow-ups [16, 18-20].

In our study, we assessed the regression of LVH with the help of LVMI measured by echocardiography at discharge and in the $1^{\text {st }}$ and $6^{\text {th }}$ months after TAVI. LVMI was observed to be decreased significantly at $1^{\text {st }}$ month after the procedure and during the clinical follow-ups compared to baseline values. Therefore, it can be propounded that the regression in LVMI and thus LVH after TAVI commences earlier and sustains during the clinical follow-ups compared to conventional s-AVR and thus will be able to reach the final values earlier. Here if we compare the conventional surgery with TAVI, we can observe that, due to the cardiopulmonary bypass, the early stage of hemodynamic effects depending on myocardial ischemia, myocardial edema and ischemia-reperfusion injury can be worse in the surgical method. The impaired diastolic functions depending on these causes can be associated with peri-operative adverse outcomes, especially in older patients [21, 22]. In a study comparing the TAVI and s-AVR in patients with AS, performed by Guarracino et al. [22], acute improvement observed in diastolic functions after TAVI had not been detected after s-AVR. They explained this by the impediment of the reduction in afterload due to the cardioplegia and cardiopulmonary bypass after s-AVR [22]. Gonçalves et al. [23] have showed the reduction of $\mathrm{LV}$ end-diastolic pressure with an invasive method just a minute after TAVI and detected this without any change in echocardiographic E/É'ratio [23]. 
Impaired LV diastolic function is an independent risk factor for early- and late-term mortality in patients with AS after s-AVR. AS leads to an increase in LV myocyte mass and additionally interstitial fibrosis. The regression of interstitial fibrosis can last long and normalization of diastolic functions can take a long time.

TAVI is performed in the older patients with high surgical risk and multiple co-morbid clinical conditions. Due to the early favorable hemodynamic effects and the retrieval of patients from cardiopulmonary bypass, it is believed to be superior compared with s-AVR. As it is shown in our study, the decrease in LVMI, which is the indicator of LVH in the early period and follow-ups after TAVI, can imply the usefulness and reliability of TAVI in patients with older age and co-morbid diseases.

\section{Limitations of the study}

The main limitation of our study was a small number of patients. The main reason of limited number of patients included into this study is the rarity of patients with AS convenient for TAVI. Therefore, larger scale studies are needed to confirm the beneficial effect of TAVI on LVH. The second issue is, although all echocardiographic examinations were performed by an experienced single operator, LVM measurement might be affected by some potential errors.

\section{Conclusions}

Our study demonstrated that TAVI is associated with a significant improvement on LVMI which is associated with $\mathrm{LVH}$ both in early period and follow-ups. TAVI is comparable to s-AVR in terms of LV reverse remodeling and superior to it due to the early favorable hemodynamic effects and the retrieval of patients from cardiopulmonary by-pass. TAVI significantly reduces the trans-aortic gradients and increases LVEF at discharge, and in the $1^{\text {st }}$ and $6^{\text {th }}$ months of follow-ups as well.

\section{Conflict of interest: None declared}

\section{References}

1. Selzer A. Changing aspects of the natural history of valvular aortic stenosis. N Engl J Med, 1987; 317: 91-99.

2. Carabello BA, Paulus WJ. Aortic stenosis. Lancet, 2009; 373: 956-966.

3. Nkomo VT, Gardin JM, Skelton TN, Gottdiener JS, Scott CG, Enriquez-Sarano M. Burden of valvular heart diseases: A population-based study. Lancet, 2006; 368: 1005-1011.

4. Lefèvre T, Kappetein AP, Wolner E et al. PARTNER EU Investigator Group. One year follow-up of the multi-centre European PARTNER transcatheter heart valve study. Eur Heart J, 2011; 32: 148-157.
5. Guadino M. Survival after aortic valve replacement for aortic stenosis:does left ventricular mass regression have a clinical correlate? Eur Heart J, 2004; 26: 51-57.

6. Lund O, Flo C, Jensen FT et al. Left ventricular systolic and diastolic function in aortic stenosis. Prognostic value after valve replacement and underlying mechanisms. Eur Heart J, 1997; 18: 1977-1987.

7. Lang RM, Bierig M, Devereux RB et al. American Society of Echocardiography's Nomenclature, Standards Committee, Task Force on Chamber Quantification, American College of Cardiology Echocardiography Committee, American Heart Association, European Association of Echocardiography, European Society of Cardiology. Recommendations for chamber quantification. Eur J Echocardiogr, 2006; 7: 79-108.

8. Zamorano JL, Badano LP, Bruce Ch et al. et al. EAE/ASE Recommendations for the Use of Echocardiography in New Transcatheter Interventions for Valvular Heart Disease. Eur Heart J, 2011; 32: 2189-2214.

9. Vizzardi E, D'Aloia A, Fiorina C et al. Early regression of left ventricular mass associated with diastolic improvement after transcatheter aortic valve implantation. J Am Soc Echocardiogr, 2012; 25: 1091-1098.

10. Levy D, Garrison RJ, Savage DD, Kannel WB, Castelli WP. Prognostic implications of echocardiographically determined left ventricular mass in the Framingham Heart Study. N Engl J Med, 1990; 322: 1561-1566.

11. Devereux RB, de Simone G, Ganau A, Roman MJ. Left ventricular hypertrophy and geometric remodeling in hypertension: Stimuli, functional consequences and prognostic implications. J Hypertens, 1994; 12: 117-127.

12. Bech-Hanssen O, Caidahl K, Wall B, Myken P, Larsson S, Wallentin I. Influence of aortic valve replacement, prosthesis type, and size on functional outcome and ventricular mass in patients with aortic stenosis. J Thorac Cardiovasc Surg, 1999; 118: 57-65.

13. Ikonomidis I, Tsoukas A, Parthenakis F et al. Four year follow-up of aortic valve replacement for isolated aortic stenosis: A link between reduction in pressure overload, regression of left ventricular hypertrophy, and diastolic function. Heart, 2001; 86: 309-316.

14. González-Juanatey JR, García-Acuña JM, Vega Fernandez M et al. Influence of the size of aortic valve prostheses on hemodynamics and change in left ventricular mass: Implications for the surgical management of aortic stenosis. J Thorac Cardiovasc Surg, 1996; 112: 273-280.

15. Lund O, Emmertsen K, Dørup I, Jensen FT, Flø C. Regression of left ventricular hypertrophy during 10 years after valve replacement for aortic stenosis is related to the preoperative risk profile. Eur Heart J, 2003; 24: 1437-1446.

16. Sharma UC, Barenbrug P, Pokharel S, Dassen WR, Pinto YM, Maessen JG. Systematic review of the outcome of aortic valve replacement in patients with aortic stenosis. Ann Thorac Surg, 2004; 78: 90-95.

17. Duncan AI, Lowe BS, Garcia MJ et al, Influence of concentric left ventricular remodeling on early mortality after aortic valve replacement. Ann Thorac Surg, 2008; 85: 2030-2039.

18. Lund O, Kristensen LH, Baandrup U et al. Myocardial structure as a determinant of pre- and postoperative ventricular function and long-term prognosis after valve replacement for aortic stenosis. Eur Heart J, 1998; 19: 1099-1108.

19. Jilaihawi H, Jeilan M, Spyt T, Chin D, Logtens E, Kovac J. Early regression of left ventricular wall thickness following percutaneous aortic valve replacement with the CoreValve bioprosthesis. Invasive Cardiol, 2009; 21: 151-155.

20. De Paulis R, Sommariva L, Colagrande L et al. Regression of left ventricular hypertrophy after aortic valve replacement for aortic stenosis with different valve substitutes. J Thorac Cardiovasc Surg, 1998; 116: 590-598.

21. Shim JK, Choi YS, Chun DH, Hong SW, Kim DH, Kwak YL. Relationship between echocardiographic index of ventricular filling pressure and intraoperative haemodynamic changes during off-pump coronary bypass surgery. Br J Anaesth, 2009; 102: 316-321.

22. Guarracino F, Talini E, Landoni G, Petronio S, Giannini C, Di Bello V. Effect of aortic valve surgery on left ventricular diastole assessed by echocardiography and neuroendocrine response: Percutaneous versus surgical approach. J Cardiothorac Vasc Anesth, 2010; 24: 25-29.

23. Gonçalves A, Marcos-Alberca P, Almeria C et al. Acute left ventricle diastolic function improvement after transcatheter aortic valve implantation. Eur J Echocardiogr, 2011; 12: 790-797. 